DISTRIBUTED FUZZY CONTROL OF MULTIVARIABLE SYSTEMS 


\section{INTERNATIONAL SERIES IN \\ INTELLIGENT TECHNOLOGIES}

Prof. Dr. Dr. h.c. Hans-Jürgen Zimmermann, Editor European Laboratory for Intelligent

Techniques Engineering Aachen, Germany

Other books in the series:

Applied Research in Fuzzy Technology

by Anca L. Ralescu

Analysis and Evaluation of Fuzzy Systems

by Akira Ishikawa and Terry L. Wilson

Fuzzy Logic and Intelligent Systems

edited by Hua Li and Madan Gupta

Fuzzy Set Theory and Advanced Mathematical Applications

edited by Da Ruan 


\title{
DISTRIBUTED FUZZY CONTROL OF MULTIVARIABLE SYSTEMS
}

\author{
by \\ ALEXANDER GEGOV \\ Institute of Control and Systems Research, \\ Bulgarian Academy of Sciences, \\ Sofia, Bulgaria
}

Springer-Science + Business Media, B.V. 


\section{Library of Congress Cataloging-in-Publication Data}

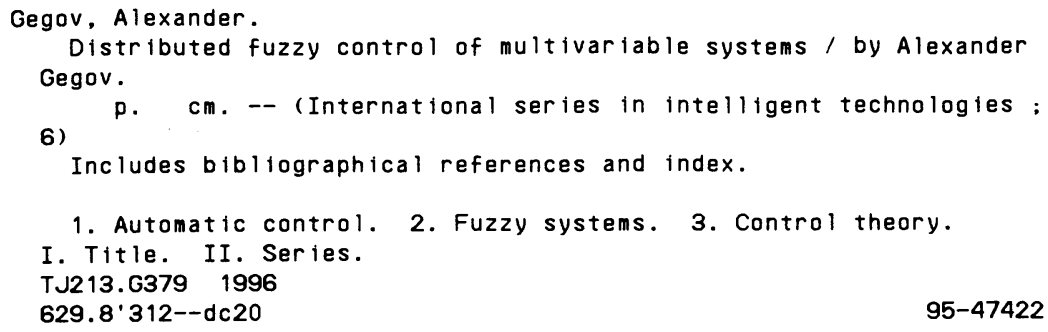

\section{All Rights Reserved}

(C) 1996 Springer Science+Business Media Dordrecht

Originally published by Kluwer Academic Publishers in 1996.

Softcover reprint of the hardcover 1st edition 1996

No part of the material protected by this copyright notice may be reproduced or utilized in any form or by any means, electronic or mechanical, including photocopying, recording or by any information storage and retrieval system, without written permission from the copyright owner. 
To my motherland 


\section{TABLE OF CONTENTS}

Preface ................... n Acknowledgements ................ . xiii Chapter 1. Introduction . . . . . . . . . . . . . . 1 Chapter 2. Dimensional reduction of fuzzy relations in multivariable control systems . . . . . . . . . . . . . . 4

2.1 Problem statement . . . . . . . . . . . . 4

2.2 Theoretical preliminaries .............. 8

2.3 Control algorithms ... . . . . . . . . . 12

2.4 Number of on-line computations . . . . . . . . . . 13

2.5 Numerical examples . . . . . . . . . . . . . . 13

2.6 Analysis of results . . . . . . . . . . . . . . . 18 Chapter 3. Decomposition of multivariable systems for distributed fuzzy control ...................... 19

3.1 Problem statement .................. 19

3.2 Theoretical preliminaries . . . . . . . . . . . . 19

3.3 Method of decomposition . . . . . . . . . . . 21

3.3.1 Introductory considerations . . . . . . . . . . . . 21

3.3.2 Decomposition algorithms ............ 26

3.4 Application to an electric power system . . . . . . . 28

3.5 Analysis of results . . . . . . . . . . . . . . 34

Chapter 4. Hierarchical fuzzy control of multivariable systems . . . 35

4.1 Problem statement . . . . . . . . . . . . 35

4.2 Theoretical preliminaries ............. 35

4.3 Method of control . . . . . . . . . . . . . . 37

4.3.1 Introductory considerations . . . . . . . . . . . . . . 38

4.3.2 Control law theorems . . . . . . . . . . . 39

4.3.3 Number of fuzzy relations . . . . . . . . . . . 40

4.3.4 Control algorithms . . . . . . . . . . . . . 41

4.4 Application to an urban traffic network ..........42

4.5 Analysis of results . . . . . . . . . . . . . . . . 49

Chapter 5. Decentralized fuzzy control of multivariable systems by passive decomposition ................ 50

5.1 Problem statement ............... 50

5.2 Theoretical preliminaries ............. 53 
5.3 Control algorithms ............... . 60

5.4 Numerical examples . . . . . . . . . . . . . 62

5.5 Analysis of results . . . . . . . . . . . . . 65

Chapter 6. Decentralized fuzzy control of multivariable systems by active decomposition ................. 67

6.1 Problem statement ................ . . 67

6.2 Theoretical preliminaries ............. . 67

6.3 Control algorithms . . . . . . . . . . . . . . 78

6.4 Numerical examples . . . . . . . . . . . . . 80

6.5 Analysis of results . . . . . . . . . . . . 86

Chapter 7. Decentralized fuzzy control of multivariable systems by direct decomposition . . . . . . . . . . . . . . 87

7.1 Problem statement . . . . . . . . . . . . 87

7.2 Theoretical preliminaries . . . . . . . . . . . 87

7.3 Control algorithms . . . . . . . . . . . . . 97

7.4 Numerical examples . . . . . . . . . . . . . . . 98

7.5 Analysis of results . . . . . . . . . . . . . . 103

Chapter 8. Multilayer fuzzy control of multivariable systems by passive decomposition . . . . . . . . . . . . . . 105

8.1 Problem statement . . . . . . . . . . . . 105

8.2 Theoretical preliminaries . . . . . . . . . . . . 106

8.3 Control algorithms . . . . . . . . . . . . 116

8.4 Numerical examples . . . . . . . . . . . . . 118

8.5 Analysis of results . . . . . . . . . . . . . . 122

Chapter 9. Multilayer fuzzy control of multivariable systems by active decomposition . . . . . . . . . . . . . . . 124

9.1 Problem statement . . . . . . . . . . . . . . 124

9.2 Theoretical preliminaries . . . . . . . . . . . . . 124

9.3 Control algorithms . . . . . . . . . . . . . 136

9.4 Numerical examples . . . . . . . . . . . . . . . 138

9.5 Analysis of results . . . . . . . . . . . . . . 143

Chapter 10. Multilayer fuzzy control of multivariable systems by direct decomposition . . . . . . . . . . . . . . . . . 144

10.1 Problem statement . . . . . . . . . . . 144

10.2 Theoretical preliminaries . . . . . . . . . . . 144

10.3 Control algorithms . . . . . . . . . . . . 154

10.4 Numerical examples . . . . . . . . . . . . . 155 
10.5 Analysis of results . . . . . . . . . . . . . . . . 160

Chapter 11. Distributed fuzzy fault diagnosis in multivariable control systems . . . . . . . . . . . . . . . . . . 162

11.1 Problem statement ................. 162

11.2 Basic stages in fault diagnosis . . . . . . . . . . 164

11.3 Application of the distributed fuzzy approach . . . . . 165

Chapter 12. Conclusions . . . . . . . . . . . . 168

Appendix . . . . . . . . . . . . . . . 170

References .................... 175

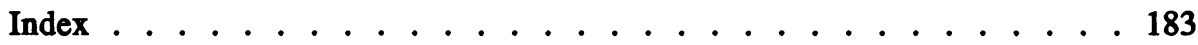




\section{PREFACE}

It is known that many control processes are characterized by both quantitative and qualitative complexity. The quantitative complexity is usually expressed in a large number of state variables, respectively high dimensional mathematical model. The qualitative complexity is usually associated with uncertain behaviour, respectively approximately known mathematical model.

If the above two aspects of complexity are considered separately, the corresponding control problem can be easily solved. On one hand, large scale systems theory has existed for more than 20 years and has proved its capabilities in solving high dimensional control problems on the basis of decomposition, hierarchy, decentralization and multilayers. On the other hand, the fuzzy linguistic approach is almost at the same age and has shown its advantages in solving approximately formulated control problems on the basis of linguistic reasoning and logical inference. However, if both aspects of complexity are considered together, the corresponding control problem becomes non-trivial and does not have an easy solution.

Modern control theory and practice have reacted accordingly to the above mentioned new challenges of the day by utilizing the latest achievements in computer technology and artificial intelligence distributed computation and intelligent operation. In this respect, a new field has emerged in the last decade, called "Distributed intelligent control systems". However, the majority of the familiar works in this field are still either on an empirical or on a conceptual level and this is a significant drawback.

This research monograph presents some recent results in distributed fuzzy control of multivariable systems. The results are obtained within a systematic investigation, extending over the empirical and conceptual level of most familiar works. Large scale systems theory and the fuzzy linguistic approach are used as tools for distributed control and intelligent modelling. In this respect, the monograph is also an 
attempt for mutual consideration of these separately developed fields.

The work is written in a structured "method-algorithm-example" form which facilitates its reading and understanding. It is suitable for undergraduate and postgraduate students, as well as researchers from the academic domain. Some of the results could be also of interest for industrial engineers, involved in implementation of fuzzy technologies.

The monograph may be used as a reference in lecture courses on intelligent control for electrical and mechanical engineers. Moreover, it could be used for similar purposes by lecturers in applied mathematics and informatics.

The work presents fundamentals and new directions for extending fuzzy control theory for multivariable and large scale systems. In this sense, its purpose is not only to show some solutions of existing problems but also to stimulate further investigations by the scientific community which could have a significant impact on modern control theory and practice.

The monograph is structured as follows: section 1 gives an introduction, section 2 is devoted to dimensional reduction of fuzzy relations in multivariable control systems, section 3 considers the problem of decomposition of multivariable systems for distributed fuzzy control, section 4 is concerned with hierarchical fuzzy control of multivariable systems, sections 5,6 and 7 consider the problem of decentralized fuzzy control of multivariable systems by passive, active and direct decomposition, sections 8,9 and 10 are concerned with multilayer fuzzy control of such systems by passive, active and direct decomposition, section 11 presents an extension of the results for distributed fuzzy fault diagnosis and section 12 gives conclusions. Some terms and definitions from fuzzy set theory are given in the Appendix. 


\section{ACKNOWLEDGEMENTS}

This work has been carried out mainly within a Research Fellowship from the Alexander von Humboldt Foundation and partly within a Research Grant from the Commission of the European Communities. In this respect, I would like to thank both Institutions for the financial support.

I am very grateful to my german academic hosts Prof. Paul Frank and Prof. Nour Eldin for the valuable recommendations to the content of the manuscript. The organizational assistance of Mrs. Sabine Bay and Mrs. Renate Wach, as well as the provision of necessary facilities by the Department of Measurement and Control at the University of Duisburg and the Department of Automatic Control and Technical Cybernetics at the University of Wuppertal are also greatly acknowledged.

I am indebted to my former research advisor Prof. Todor Stoilov and the Director of the Institute of Control and Systems Research at the Bulgarian Academy of Sciences Prof. Jordan Zaprianov for the cooperation with regard to this research. I would also like to thank my wife Juliet for her patience and understanding. Last but not least, I am very thankful to my friends and relatives who did not forget me during my long absence abroad and especially to my colleagues from the rock-band "Argus" who helped me to feel the inspiration of music.

\section{Alexander Gegov}

